GASTRIC MOTILITY

\title{
Antro-pyloro-duodenal motor responses to gastric and duodenal nutrient in critically ill patients
}

\author{
M Chapman, R Fraser, R Vozzo, L Bryant, W Tam, N Nguyen, B Zacharakis, R Butler, \\ G Davidson, M Horowitz
}

Gut 2005;54:1384-1390. doi: 10.1136/gut.2005.065672

See end of article for authors' affiliations

Correspondence to:

Dr M Chapman, Intensive

Care Unit, Royal Adelaide

Hospital, North Terrace,

Adelaide, South Australia

5000, Australia;

mchapman@

mail.rah.sa.gov.au

Revised version received 30 March 2005

Accepted for publication

12 April 2005

Published online first

29 May 2005 yed in critical illness which compromises the success of Background: Gastric emptying is frequently delayed in critical illness which
nasogastric nutrition. The underlying motor dysfunctions are poorly defined.

Aims: To characterise antro-pyloro-duodenal motility during fasting, and in response to gastric and duodenal nutrient, as well as to evaluate the relationship between gastric emptying and motility, in the critically ill.

Subjects: Fifteen mechanically ventilated patients from a mixed intensive care unit; 10 healthy volunteers. Methods: Antro-pyloro-duodenal pressures were recorded during fasting, after intragastric administration $(100 \mathrm{ml} ; 100 \mathrm{kcal})$, and during small intestinal infusion of liquid nutrient (6 hours; $1 \mathrm{kcal} / \mathrm{min})$. Gastric emptying was measured using a ${ }^{13} \mathrm{C}$ octanoate breath test.

Results: In healthy subjects, neither gastric nor small intestinal nutrient affected antro-pyloro-duodenal pressures. In patients, duodenal nutrient infusion reduced antral activity compared with both fasting and healthy subjects $(0.03(0-2.47)$ waves $/ \mathrm{min} v 0.14(0-2.2)$ fasting $(p=0.016)$; and $v 0.33(0-2.57) / \mathrm{min}$ in healthy subjects $(p=0.005))$. Basal pyloric pressure and the frequency of phasic pyloric pressure waves were increased in patients during duodenal nutrient infusion $(3.12(1.06) \mathrm{mm} \mathrm{Hg} ; 0.98(0.13) / \mathrm{min})$ compared with healthy subjects $(-0.44$ (1.25) mm Hg; $\mathrm{p}<0.02$ after 120 minutes; 0.29 (0.15)/min; $p=0.0002)$ and with fasting $(-0.06(1.05) \mathrm{mm} \mathrm{Hg} ; \mathrm{p}<0.03$ after 160 minutes; 0.49 (0.13)/min; $(p=0.0001)$. Gastric emptying was delayed in patients (gastric emptying coefficient $2.99(0.2)$ v 3.47 (0.1); $p=0.015)$ and inversely related to the number of pyloric pressure waves $(r=-0.563, p=0.029)$. Conclusions: Stimulation of pyloric and suppression of antral pressures by duodenal nutrient are enhanced in the critically ill and related to decreased gastric emptying.
27 astric emptying is delayed in a substantial number of critically ill patients. ${ }^{1-5}$ Thus although enteral feeding is considered the optimal method for critically ill patients, ${ }^{6}$ when fed nasogastrically patients receive only about half of their nutritional goals. ${ }^{7-9}$ As well as compromising nutrition, delayed gastric emptying may be associated with an increased risk of both pulmonary aspiration ${ }^{10}$ and bacterial overgrowth. ${ }^{11}$

In health, nutrient delivery from the stomach to the small intestine is tightly regulated at $2-3 \mathrm{kcal} / \mathrm{min}^{12}$ by small intestinal feedback. Small intestinal glucose ${ }^{13}$, lipid, ${ }^{14}$ and amino acid ${ }^{15}$ infusions stimulate pyloric and suppress antral and duodenal motility. The increase in pyloric motility is associated with slowing of gastric emptying ${ }^{16}$ as a consequence of occlusion of transpyloric flow. ${ }^{17}$ In theory, abnormally slow gastric emptying may result from primary motor dysfunction ("pump failure"), disproportionate activation of normal motor mechanisms by increased intestinal feedback triggered by the presence of nutrients in the small intestine ("excessive feedback"), ${ }^{18} 19$ or a combination of the two.

It has hitherto been assumed that delayed gastric emptying observed in critically ill patients is due to "pump failure" characterised by antral hypomotility. ${ }^{20}$ The motor dysfunctions responsible for slow gastric emptying in the critically ill are poorly defined, and the amount of available information is limited. ${ }^{21-25}$ Early studies documented reduced postprandial antral activity and absent fasting antral activity fronts, with relatively normal numbers of duodenal pressure waves ${ }^{21}$ and, possibly, more frequent activity fronts. ${ }^{23}$ The persistence of fasting activity during feeding is a feature of critical illness ${ }^{22-26}$ which may compromise the success of jejunal nutrition. ${ }^{26}$ No studies have evaluated pyloric motility in the critically ill. The possibility that increased small intestinal nutrient feedback contributes to delayed gastric emptying has also not been assessed. The aims of this study were to assess the effect of critical illness on antral and duodenal motility and pyloric pressures, during fasting, during gastric emptying of nutrient, and during intraduodenal infusion of nutrient.

\section{MATERIALS AND METHODS \\ Subjects}

Studies were performed in 15 mechanically ventilated adult patients in a tertiary referral mixed intensive care unit (ICU). Demographic characteristics of the cohort are shown in table 1 . The primary diagnosis of patients resulting in ICU admission is shown in table 2. All patients were either receiving, or suitable for, nasogastric feeding. Median rate of feed prior to the study was $63 \mathrm{ml} / \mathrm{h}$ (range $0-80$ ). Eight of the fifteen patients were intolerant of feeds (that is, a gastric aspirate volume $>250 \mathrm{ml}$ at some time in the preceding 24 hours). ${ }^{8}$ Patients were excluded from participation if they had any of the following: cervical spine injury, increased intracranial pressure, compromised coronary perfusion, contraindication to passage of an enteral tube, requirement for opiate analgesia, and contraindication to the use of propofol.

Abbreviations: GEC, gastric emptying coefficient; APD, antro-pyloroduodenal; TMPD, transmucosal potential difference; IPPWs, isolated pyloric pressure waves; MMC, migrating motor complex; ICU, intensive care unit 
No patient had undergone abdominal surgery, had known diabetes mellitus, or a history of excessive alcohol intake. Ten of the 15 patients had received opiates within the 48 hour period (mean 20.5) prior to commencing the study. Median blood glucose concentration at baseline was 6.7 (4.511) $\mathrm{mmol} / \mathrm{l}$. Data were compared with 10 healthy volunteers aged 21 years $(19-40)(\mathrm{p}<0.001)$. The study was approved by the Royal Adelaide Hospital Research Ethics Committee and performed according to the National Health and Medical Research Committee Guidelines for the conduct of research on unconscious patients. Informed consent was obtained from next of kin.

Following an overnight fast in the volunteers, or a fast of at least 4 hours (mean 7.55 (3) h; one patient had not commenced feeding prior to the study) in patients, recordings of antro-pyloro-duodenal (APD) pressures were performed during fasting (six hours), during small intestinal infusion of enteral feed (Ensure; Abbott, Australasia Pty Ltd, Botany, New South Wales, Australia) $1 \mathrm{kcal} / \mathrm{ml} ; 37.2 \mathrm{~g} / \mathrm{l}$ fat (corn oil), $37.2 \mathrm{~g} / \mathrm{l}$ protein (sodium and calcium caseinates), $145 \mathrm{~g} / \mathrm{l}$ carbohydrate (corn syrup/sucrose); $50 \mathrm{ml} / \mathrm{h}$; six hours), and following a gastric bolus of $100 \mathrm{ml}$ enteral feed (four hours). The three study periods were randomised and allocated by sealed envelope. Volunteers were studied on three separate days. All subjects were studied supine at $30^{\circ}$ head elevation.

\section{Measurements}

Intraluminal pressures in the distal stomach, pylorus, and proximal duodenum were recorded using a water perfused portable manometric system. ${ }^{14} 27$ A weighted, silicone, multilumen tube of $3.5 \mathrm{~mm}$ outer diameter, incorporating a sleeve sensor and side holes with an infusion port located $2.75 \mathrm{~cm}$ from the tip, was introduced transnasally. The sleeve sensor was positioned across the pylorus using an endoscopic technique in patients and by normal peristalsis in healthy subjects. Side holes were located every $1.5 \mathrm{~cm}$ from the infusion port (Dentsleeve, Adelaide, South Australia). Measurement of antro-duodenal transmucosal potential difference (TMPD) gradient was used to ensure the position of the sleeve sensor across the pylorus ${ }^{142728}$ so that five side
Table 2 Primary diagnosis of patients resulting in intensive care unit admission

\begin{tabular}{ll}
\hline Patient & Diagnosis \\
\hline 1 & Brain tumour \\
2 & Sepsis \\
3 & Sepsis \\
4 & Respiratory failure/asthma \\
5 & Respiratory failure/aspiration \\
6 & Chest trauma \\
7 & Respiratory failure \\
8 & Ruptured thoracic aortic aneurysm \\
9 & Respiratory failure \\
10 & Pancreatitis \\
11 & Head injury \\
12 & Ruptured abdominal aortic aneurysm repair \\
13 & Sepsis \\
14 & Respiratory failure \\
15 & Trauma/paraplegia \\
\hline
\end{tabular}

holes were located in the antrum and six in the duodenum. Each lumen was connected to a pressure transducer and perfused with gas free distilled water (or saline for TMPD channels) by an infusion pump at a rate of 0.08 (side holes) or 0.15 (sleeve sensor) $\mathrm{ml} / \mathrm{min}$. Outputs from pressure transducers were recorded online at $10 \mathrm{~Hz}$ with a Power Macintosh computer (7100/80; Apple, Cuppertino, California, USA) using previously validated ${ }^{29}{ }^{30}$ custom written software developed inhouse (MAD, CH Malbert), written in Labview 3.0.1 (National Instruments, Austin, Texas, USA), and logged directly to disk for subsequent analysis.

APD pressure recordings were analysed manually, and only when the assembly was positioned correctly according to established TMPD criteria. ${ }^{14}$ In each subject the second antral and duodenal channels were used to determine wave frequency. Pressure waves were counted when their amplitude was at least $6 \mathrm{~mm} \mathrm{Hg}^{31}$; artefacts due to straining and coughing were excluded. Isolated pyloric pressure waves (IPPWs) were defined as pressure waves of at least $10 \mathrm{~mm} \mathrm{Hg}$ amplitude recorded only in the sleeve channel. ${ }^{14}$ Wave frequencies were determined for the whole of the study

Table 1 Characteristics of the critically ill patients

\begin{tabular}{|c|c|c|c|c|c|c|c|c|c|c|c|c|}
\hline $\begin{array}{l}\text { Patient } \\
\text { No }\end{array}$ & $\begin{array}{l}\text { Age } \\
\text { (y) }\end{array}$ & Sex & $\begin{array}{l}\text { Fast } \\
\text { (h) }\end{array}$ & $\begin{array}{l}\text { Days in } \\
\text { ICU }\end{array}$ & APACHE II & Outcome & Glucose & GEC & Dialysis & Insulin & Propofol & Inotropes \\
\hline 1 & 64 & $M$ & 11 & 4 & 16 & Died & 4.5 & 3.32 & $N$ & $Y$ & $Y$ & $Y$ \\
\hline 2 & 57 & $M$ & 6 & 4 & 26 & Alive & 11 & 3.48 & $N$ & $\mathrm{~N}$ & $\mathrm{~N}$ & $\mathrm{~N}$ \\
\hline 3 & 46 & $M$ & 5 & 10 & 17 & Died & 9.1 & 2.9 & $Y$ & $Y$ & $Y$ & $Y$ \\
\hline 4 & 58 & $\mathrm{~F}$ & 13 & 11 & 21 & Alive & 7.7 & 2.64 & $N$ & $Y$ & $Y$ & $\mathrm{~N}$ \\
\hline 5 & 74 & $\mathrm{~F}$ & 10 & 5 & 12 & Alive & 8 & 3.94 & $\mathrm{~N}$ & $Y$ & $Y$ & $Y$ \\
\hline 6 & 49 & $M$ & 11 & 4 & 12 & Alive & 6.1 & 1.8 & $N$ & $Y$ & $Y$ & $\mathrm{~N}$ \\
\hline 7 & 70 & $M$ & 7 & 3 & 12 & Died & 5 & 2.34 & $N$ & $Y$ & $Y$ & $Y$ \\
\hline 8 & 72 & $M$ & 7 & 11 & 14 & Died & 5 & 3.28 & $Y$ & $Y$ & $Y$ & $Y$ \\
\hline 9 & 46 & $M$ & 8 & 7 & 10 & Alive & 5.7 & 3.29 & $\mathrm{~N}$ & $Y$ & $Y$ & $Y$ \\
\hline 10 & 38 & $M$ & 7 & 102 & 13 & Alive & 7.2 & 3.48 & $\mathrm{~N}$ & $Y$ & $\mathrm{~N}$ & $Y$ \\
\hline 11 & 19 & $M$ & 6 & 7 & 17 & Alive & 5.8 & 3.31 & $\mathrm{~N}$ & $\mathrm{~N}$ & $\mathrm{~N}$ & $Y$ \\
\hline 12 & 55 & $M$ & 168 & 7 & 14 & Alive & 7.7 & 3.74 & $N$ & $N$ & $Y$ & $N$ \\
\hline 13 & 31 & $\mathrm{~F}$ & 6 & 8 & 20 & Alive & 6.5 & 1.7 & $N$ & $Y$ & $N$ & $Y$ \\
\hline 14 & 74 & $M$ & 5 & 8 & 17 & Alive & 7.6 & 2.56 & $Y$ & $Y$ & $Y$ & $\mathrm{~N}$ \\
\hline 15 & 38 & $\mathrm{~F}$ & 5 & 4 & 15 & Alive & 6.7 & 3.01 & $\mathrm{~N}$ & $Y$ & $Y$ & $\mathrm{~N}$ \\
\hline Median & 55 & $4 \mathrm{~F}$ & 7 & 7 & 15 & 4 died & 6.7 & 2.99 & 3 & 12 & 11 & 9 \\
\hline Range & 19-74 & & $5-168$ & $4-102$ & $10-26$ & & $4.5-11$ & $1.7-3.94$ & & & & \\
\hline
\end{tabular}

"Fast" refers to the period of time that the patient fasted prior to the study.

"Days in ICU" are the days prior to the performance of the study.

APACHE II score is the acute physiology and chronic health evaluation score which gives a measure of sickness severity. This was determined on the day of study. (Median admission APACHE II score was 20.)

"Outcome" refers to hospital outcome.

"Glucose" refers to baseline blood glucose concentration (mmol/l).

GEC, gastric emptying coefficient.

The use of dialysis, intravenous insulin infusion, propofol infusion, and inotropes (adrenaline and noradrenaline infusion only) are indicated.

Data are median (range) or number. 
Table 3 Antro-pyloro-duodenal pressures and gastric emptying during fasting, duodenal infusion of nutrient, and after a gastric nutrient bolus in critically ill patients and healthy subjects

\begin{tabular}{|c|c|c|c|c|c|c|}
\hline & \multicolumn{2}{|l|}{ Fasting } & \multicolumn{2}{|c|}{ Duodenal nutrient infusion } & \multicolumn{2}{|c|}{ Gastric nutrient bolus } \\
\hline & Healthy & ICU & Healthy & ICU & Healthy & ICU \\
\hline Antral waves/min (median (range)) & $0.22(0-2.34)$ & $0.14(0-2.2) \dagger$ & $0.33(0-2.57)^{*}$ & $0.03(0-2.47)$ & $0.42(0-2.67)^{*}$ & $0.06(0-3.1)$ \\
\hline IPPWs/min & $0.23(0.14)$ & $0.49(0.13) \dagger$ & $0.29(0.15)^{*}$ & $0.98(0.13)$ & $0.22(0.15)$ & $0.48(0.13)$ \\
\hline Pyloric tone $(\mathrm{mm} \mathrm{Hg})$ & $0.30(1.24)$ & $-0.06(1.05)$ & $-0.44(1.25)$ & $3.12(1.06)$ & $1.04(1.29)$ & $-0.21(1.06)$ \\
\hline Duodenal waves/min & $1.5(0.36)$ & $1.5(0.28)$ & $1.7(0.32)$ & $1.9(0.27)$ & $1.7(0.32)$ & $2.2(0.29)$ \\
\hline Antral phase $3 / \mathrm{h}$ & $1.9(0.17)^{*} \dagger$ & $0.14(0.15)$ & $0.3(0.17)$ & $0.06(0.14)$ & & \\
\hline Duodenal phase $3 / \mathrm{h}$ & $2.9(1.16)$ & $4.33(0.96)$ & $1(1.16)$ & $3.33(0.95)$ & & \\
\hline GEC & & & & & $3.47(0.1)^{*}$ & $2.99(0.2)$ \\
\hline
\end{tabular}

Values are mean (SEM) except when stated.

ICU, intensive care unit; IPPWs, isolated pyloric pressure waves; GEC, gastric emptying coefficient.

Significance difference: *healthy versus ICU; ffasting versus duodenal nutrient infusion.

periods and analysed in 30 minute time intervals. Change in pyloric tone (basal pyloric pressure) was calculated as the difference in baseline pressure in the sleeve sensor from the duodenum, ${ }^{32}$ and was calculated for the whole of the study period and analysed in 20 minute time blocks. Antral "burst" or phase III activity was defined as rhythmic pressure wave activity occurring at maximum frequency (three pressure waves per minute) for at least one minute in a temporal relationship with duodenal phase III activity. ${ }^{23}{ }^{25}$ Duodenal phases of the migrating motor complex (MMC) were defined as follows: phase I, quiescence, no more than two pressure waves per 10 minutes for at least five minutes and preceded by phase III; phase II, irregular activity with pressure waves at a rate of more than two per 10 minutes; phase III/burst, regular pressure wave activity at a maximum frequency of 10-12 pressure waves per minute for at least two minutes followed by motor quiescence (phase I). ${ }^{23}$ Episodes of "atypical" burst activity (that is, high frequency pressure waves not fulfilling all of the above criteria for phase 3) were also documented. MMC periodicity, time to first MMC or burst activity after gastric bolus, and percentage of time in phases were calculated.

Gastric emptying was measured with a ${ }^{13} \mathrm{C}$ octanoate breath test that has been used previously in the critically ill. ${ }^{43}$ In both patients and healthy subjects, $100 \mu$ l octanoate $(100 \mathrm{mg} / \mathrm{ml})$ was mixed with $100 \mathrm{ml}$ Ensure and instilled into the stomach over five minutes via a nasogastric tube. In patients, end expiratory breath samples were collected from the ventilation tube using a $\mathrm{T}$ adapter (Datex-Engstrom, Helsinki, Finland) and holder for vacutainers (blood needle holder; Reko, Lisarow, Australia), containing a needle (VenoJect; Terumo Corporation, Tokyo, Japan). This technique allowed the reliable filling of collection tubes (Exetainer, Buckinghamshire, UK) ${ }^{4}$ Healthy subjects fully expired into sample tubes for collection of end expiratory breath samples. Breath samples were collected immediately before instillation of the Ensure, every five minutes for the first hour, and every 15 minutes thereafter for a further three hours. Breath samples were analysed for ${ }^{13} \mathrm{CO}_{2}$ concentration using an isotope ratio mass spectrometer (Europa Scientific, ABCA model 20\20, Crewe, UK). The ${ }^{13} \mathrm{CO}_{2}$ concentration in each sample was plotted over time and the area under the recovery curve was used to calculate the gastric emptying coefficient (GEC).$^{34}$ Using this technique, we have previously documented a normal range for GEC of 3.2-3.8 in healthy subjects. ${ }^{4}$

\section{Statistical analysis}

Data were assessed for normality and the results expressed as mean (SEM) or median (range), as appropriate. As the antral wave frequency data were not normally distributed, data were $\log$ transformed for statistical analysis and are presented as medians (ranges). The Student's $t$ test and Mann Whitney U test were used, as appropriate, to compare groups. Analysis of wave frequency was by mixed model ANOVA to allow for missing data. Pearson correlation coefficient was used to examine the relationship between GEC and IPPWs, antral waves and pyloric tone. A p value $<0.05$ was considered significant.

\section{RESULTS}

The study was well tolerated by both patients and volunteers. One patient experienced minor bleeding as a result of a pharyngeal abrasion. The sleeve was positioned correctly $98 \%$ of the time in healthy subjects and $87 \%$ of the time in patients.

In healthy subjects, all burst activity fulfilled the criteria for phase 3. In patients, $38 \%$ of episodes of burst activity were "atypical", usually because they were not followed by

Table 4 Percentage of time in phases of migrating motor complex

\begin{tabular}{|c|c|c|c|c|c|c|}
\hline & \multicolumn{3}{|l|}{ Fasting } & \multicolumn{3}{|c|}{ Duodenal nutrient infusion } \\
\hline & Quiescence & Irregular & Burst & Quiescence & Irregular & Burst \\
\hline \multicolumn{7}{|l|}{ Antral } \\
\hline Healthy & $24(26)$ & $74(28)$ & $3(2)$ & $0(5)$ & 100 (7) & $0(1)$ \\
\hline Patients & $0(8)$ & $100(9)$ & $0(0.3)$ & $0(1)$ & $100(1)$ & $0(0)$ \\
\hline p Value & 0.001 & 0.001 & $<0.001$ & NS & NS & NS \\
\hline \multicolumn{7}{|l|}{ Duodenal } \\
\hline Healthy & 14 (19) & $82(21)$ & $5(4)$ & $0.5(8)$ & $99(13)$ & $0.5(4.5)$ \\
\hline Patients & $11(28)$ & $72(42)$ & 4 (14) & $6(29)$ & $81(40)$ & $4(2)$ \\
\hline $\mathrm{p}$ Value & NS & NS & NS & NS & 0.06 & 0.07 \\
\hline
\end{tabular}

Values are median (interquartile range).

Definitions are shown in the text.

The Mann-Whitney $U$ test was used for analysis.

Administration of duodenal nutrient to healthy subjects caused less burst activity and quiescence compared with fasting in both the antrum and duodenum $(p<0.01)$. 

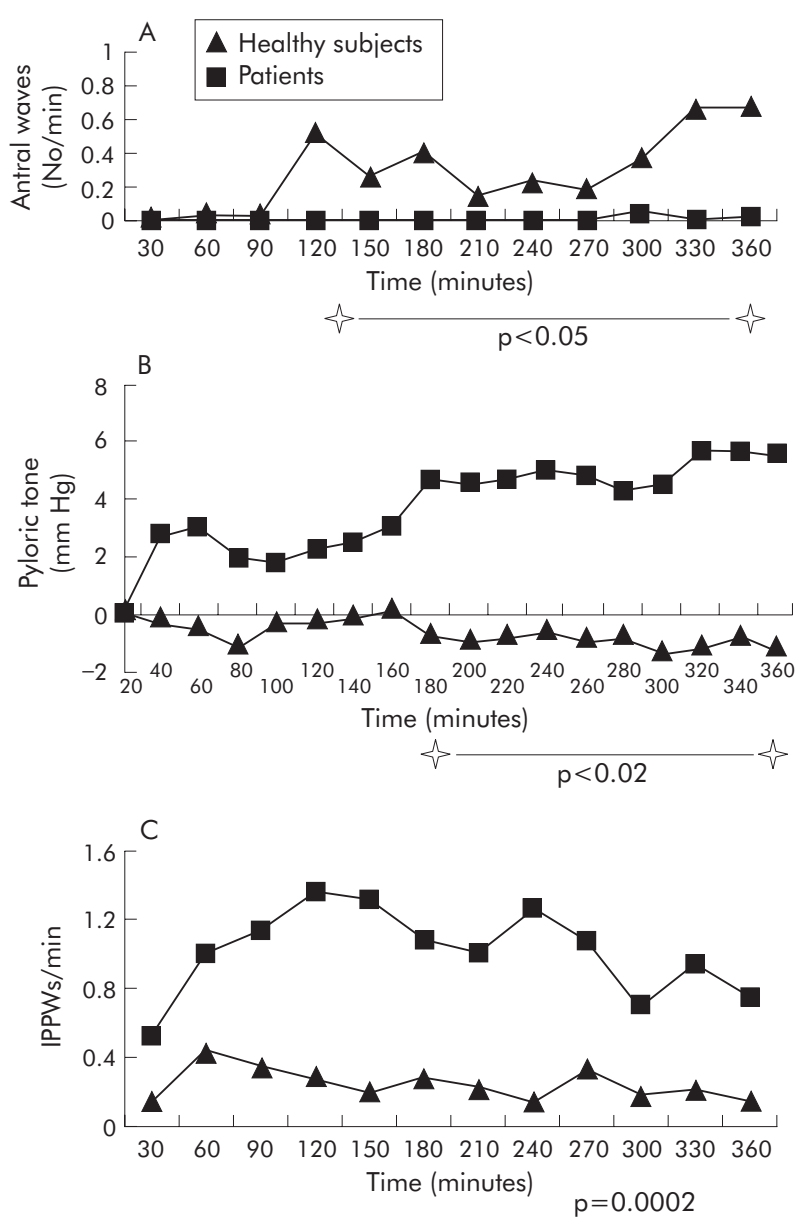

Figure 1 Antral wave frequency $(A)$, pyloric tone (B), and (C) isolated pyloric pressure wave (IPPW) frequency over time during duodenal infusion of nutrient in patients and healthy subjects. quiescence. The results are shown in table 3 . The periodicity of duodenal burst activity during fasting tended to be less in patients than in healthy volunteers $(68$ (20) $v 122$ (21) minutes; $\mathrm{p}=0.08$ ). The proportion of time spent in quiescence, irregular activity, and burst activity is shown in table 4 .

In patients, during small intestinal nutrient infusion, antral wave frequency was decreased compared with both fasting and healthy subjects (table 3 ) in whom antral wave frequency increased over time $(\mathrm{p}<0.05$ after 120 minutes $)$ (fig 1). During small intestinal nutrient infusion, the number of IPPWs was higher in patients compared with both fasting and healthy subjects (table 3, fig 1). An example of the motor responses is shown in fig 2 . Small intestinal nutrient infusion stimulated pyloric tone in patients but not in healthy subjects (table 3, fig 1).

Breath samples were unsuitable for analysis in one subject in the healthy group. Gastric emptying was slower in patients (table 3) and seven patients had a GEC that was outside (that is, slower than) the normal range. None of the healthy subjects had delayed gastric emptying. There was an inverse relationship between the GEC and IPPW frequency in patients $(r=-0.563, \mathrm{p}=0.029)$ but not in healthy subjects $(r=-0.33, \mathrm{p}=0.38)$. The relationship between GEC and pyloric tone was not significant in either group (patients $r=-0.18, \mathrm{p}=0.52$; healthy subjects $r=-0.5, \mathrm{p}=0.17)$; this was also the case for the relationship between GEC and antral wave frequency (patients $r=0.372, \mathrm{p}=0.172$; healthy subjects $r=0.01, \mathrm{p}=0.97)$.

In patients, there was no difference in GEC in those who were receiving catecholamines compared with those who were not (data not shown). There was no significant relationship between blood glucose and GEC or pyloric activity (data not shown).

\section{DISCUSSION}

This study represents the first evaluation of pyloric motility, the effects of small intestinal nutrient on APD motility, as well as the relationship between motility and gastric

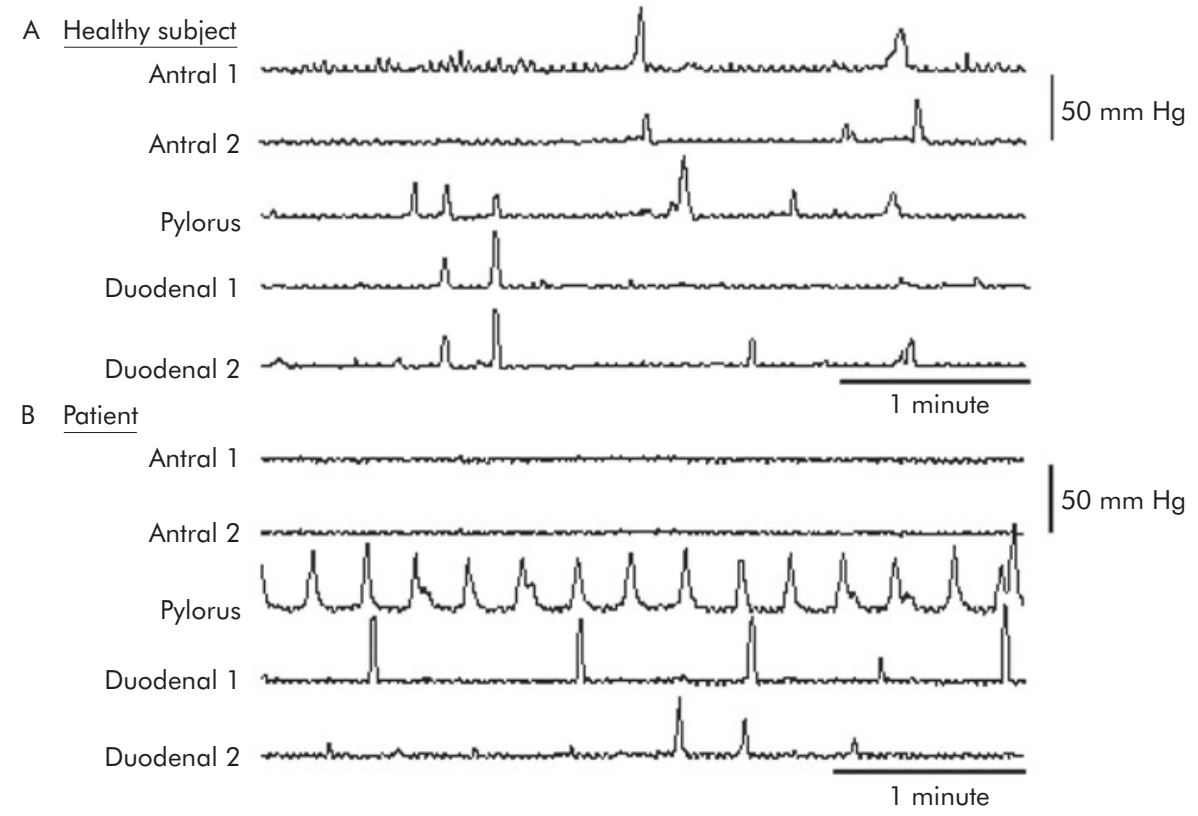

Figure 2 A five minute recording of pressure waves in two antral, one pyloric, and two duodenal channels in a healthy volunteer (A) and a patient (B) during small intestinal infusion of nutrient. Absence of antral activity and frequent isolated pyloric pressure waves are evident in the patient. 
emptying in the critically ill. The major observation is that duodenal nutrient infusion at a rate of energy delivery which approximates $50 \%$ of that which occurs during normal gastric emptying ${ }^{12}$ suppresses antral pressure waves and stimulates both tonic and phasic pyloric pressures in critically ill, but not healthy, subjects. The results confirm that gastric emptying of a liquid nutrient is delayed in about $50 \%$ of critically ill patients, and demonstrate that there is an inverse relationship between gastric emptying and phasic pyloric activity. Our observations relating to interdigestive motor activity complement those from previous studies ${ }^{21-25}$ in that critically ill patients have less antral MMC activity with similar, or a tendency to more frequent but atypical, duodenal MMC activity and a lack of inhibition of fasting motility by nutrient.

Delayed gastric emptying is a significant problem, ${ }^{12458}$ compromising nasogastric nutrition and, possibly, outcome in the critically ill. The cause of the delay in gastric emptying remains unclear and the underlying motor dysfunctions have been poorly defined. In health, gastric emptying occurs in a pulsatile fashion and the integration of motor activity in the proximal and distal stomach and proximal small intestine $e^{35}$ is responsible for transpyloric movement of chyme. ${ }^{35}{ }^{36}$ These factors are exquisitely sensitive to feedback from small intestinal nutrient receptors acting via neurohumoral pathways, limiting gastric emptying to $2-3 \mathrm{kcal} / \mathrm{min} .{ }^{12}$ Delivery of glucose at or above this rate into the small intestine suppresses gastric contractile activity and stimulates pyloric activity to retard transpyloric flow. ${ }^{13}$ This study establishes that nutrient delivery at a rate of only $1 \mathrm{kcal} / \mathrm{min}$ triggers mechanisms which retard pyloric flow in the critically ill, but not in healthy subjects.

Small intestinal feedback on APD motility and gastric emptying is dependent on the type of nutrient administered. ${ }^{18}$ The effects of triglyceride on pyloric motility are greater than an equicaloric glucose $\operatorname{load}^{13}{ }^{14} 18 ; 1 \mathrm{kcal} / \mathrm{min}$ infusion of fat (Intralipid 10\%; $10 \mathrm{~g}$ fat/100 $\mathrm{ml}$ ) reduces antral and increases pyloric activity in healthy subjects. In healthy subjects in this study, $1 \mathrm{kcal} / \mathrm{min}$ of Ensure $(3.7 \mathrm{~g}$ fat $/ 100 \mathrm{ml}$ ) had no effect on antral or pyloric activity. The different responses observed in these studies are likely to be attributable to the fat content of the nutrient. It would be of interest to evaluate the response of gastric emptying in the critically ill to a nutrient with a lower fat content as this may potentially result in less gastric inhibition and thereby increase the success of feeding. We demonstrated an inverse association between pyloric activity and gastric emptying in keeping with our understanding of the motor control of gastric emptying. ${ }^{16}$ We have also characterised the motor response of the distal stomach and proximal duodenum. Proximal stomach function and its contribution to the delays in gastric emptying remain to be examined. Our observations introduce a novel explanation for the delays in gastric emptying seen in the critically ill, which is that control of gastric emptying in these patients is hypersensitive to feedback from small intestinal nutrient.

A number of factors may contribute to slow gastric emptying and disordered motility in the critically ill, including drugs such as narcotics or catecholamines, electrolyte abnormalities such as hyperglycaemia, recent surgery, shock, circulating cytokines, or the disease process itself. ${ }^{37}$ Opiates and catecholamines (both endogenous and administered) may be responsible for abnormalities of upper gastrointestinal motor function. ${ }^{38}$ Morphine and pethidine slow gastric emptying and increase phase 3 frequency, ${ }^{39} 40$ and pethidine reduces antral contractions. ${ }^{40}$ While our patients were sedated using propofol rather than narcotics, we cannot exclude an effect of endogenous opiates which are elevated during stress or opiates administered previously. Low doses of propofol have no effect on gastric emptying in health ${ }^{41}{ }^{42}$ but propofol has been reported to be associated with feed intolerance in head injured patients. ${ }^{43}$ The effect of propofol on APD motor activity is not known. Catecholamines are frequently used to support blood pressure in the critically ill. Adrenaline slows gastric emptying by a beta adrenergic effect. ${ }^{45}{ }^{46}$ Dopamine reduces antral contractions, shortens MMC duration, ${ }^{24}$ and slows gastric emptying and orocaecal transit time, ${ }^{44}$ but dopamine was not administered to our patients and it is unclear whether these effects would also occur with other catecholamines. While nine of our 15 patients were receiving catecholamines (adrenaline or noradrenaline), there was no demonstrable association with delayed gastric emptying. Aging is also associated with a small but measurable slowing in gastric emptying, ${ }^{47} 48$ however, although the critically ill patients were older than the healthy subjects, it is most unlikely that age is responsible for the observed differences in motility or gastric emptying. We and others have demonstrated that acute elevations in blood glucose concentrations can slow motility ${ }^{49}$ and hyperglycaemia due to insulin resistance occurs frequently in the critically ill. It is however unlikely that hyperglycaemia contributed significantly to the delayed gastric emptying observed in the critically ill in this study in that median blood glucose at baseline was only $6.7 \mathrm{mmol} / \mathrm{l}$ and, as is accepted practice, $^{51}$ blood glucose levels were closely controlled requiring the use of an insulin infusion in 12 cases.

It is possible that the increased feedback and delay in gastric emptying is induced by prior fasting. Previous studies $^{52-55}$ demonstrated that gastric emptying and gastroduodenal motility are influenced by prior patterns of nutrient intake and, in particular that nutrient deprivation slows gastric emptying. ${ }^{56}{ }^{57}$ This is evident as early as four days. In approximately $50 \%$ of patients with anorexia nervosa, gastric emptying is delayed, ${ }^{55} 59$ and this normalises with recommencement of adequate intake before weight gain occurs. ${ }^{55}$ In many ICU patients there is likely to have been a period of time prior to admission when nutrition has been suboptimal, and frequently nutritional needs are not addressed immediately following admission due to the priorities of resuscitation. In an audit of nutrition practices in our ICU, the interval from admission to initiation of feeding was a mean of four days. ${ }^{8}$ The mechanisms which underlie the alterations in gastric emptying, occurring in response to variations in gastrointestinal nutrient exposure, almost certainly arise from the small intestine. ${ }^{5500}$ It is not known whether adaptive changes in gastric emptying occur as a result of changes in small intestinal receptor affinity and/or the number of receptors exposed to nutrient.

Manometric studies have rarely been performed in the critically ill population. ${ }^{21-25}$ Duodenal MMC intervals are highly variable in both health and critical illness but appear to be shorter in the latter. ${ }^{21-25}$ In the critically ill, the mean MMC duration during fasting ranges from 32 to 91 minutes $^{21-25}$ and may be shortened by the use of opiates ${ }^{23}$ or dopamine, ${ }^{24}$ and increases as patients recover. ${ }^{23}$ In this study, the duodenal MMC interval fell within this range and tended to be shorter than in healthy subjects. In the critically ill, it has been reported that proportionally more time is spent in phase 1 (quiescence) and less in phase 2 (irregular activity) than in healthy subjects. ${ }^{21} 23$ This latter observation was not evident in our study. The lack of concordance with previous data may potentially reflect the effect of opiate administration in the earlier studies. Further studies are indicated to examine this issue in greater depth. In the critically ill, it has been reported that MMC activity is not suppressed by the introduction of nasogastric nutrition. ${ }^{22}{ }^{25}$ This is supported by our study even though the nutrient dose was sufficient to reduce activity fronts in healthy subjects. It is unclear why a small dose of duodenal nutrient suppresses gastric emptying 
by reducing antral activity and increasing pyloric activity, but does not reduce fasting MMC activity in this patient group. This may imply different mechanisms for the regulation of postprandial motility and gastric emptying.

Previous studies have demonstrated a high prevalence of delayed gastric emptying in unselected cohorts of critically ill patients as well as in particular diagnostic groups such as head and spinal cord injuries. ${ }^{1245837}$ Unfortunately, there is at present insufficient information to define at risk groups. It is however probable that critical illness per se has a similar effect on gastric motility, irrespective of the underlying diagnosis ${ }^{478}$ as the stomach and small intestine appear to have a limited repertoire of responses, whatever the aetiology of the perturbation. It is accordingly likely that those who exhibit delayed gastric emptying will have similar underlying abnormal motility patterns.

Our observations suggest that in the critically ill there is hypersensitivity to small intestinal nutrient leading to motility changes which result in reduced gastric emptying. The causes and mediators of this effect remain to be determined. Further studies in these patients examining the role of sedative drugs, neurohumoral pathways (perhaps particularly cholecystokinin levels), and the effects of different nutrients are required to allow the development of therapeutic strategies. As duodenal motility appeared to be relatively normal the postpyloric delivery of nutrient may potentially prove more effective. While antral and pyloric activity were hypersensitive to the effects of small intestinal nutrient, nutrient infusion had no effect on fasting gastrointestinal MMC frequency.

\section{ACKNOWLEDGEMENTS}

This study was supported by grants from the Australian and New Zealand College of Anaesthetists and the National Health and Medical Research Council of Australia. Grateful thanks to Emmae Ramsey and Kristyn Willson of the Department of Public Health, University of Adelaide, for statistical advice and assistance.

\section{Authors' affiliations}

M Chapman, Intensive Care Unit, Royal Adelaide Hospital, North Terrace, Adelaide, Australia

R Fraser, Department of Gastroenterology, Repatriation General Hospital, Adelaide, Australia

R Vozzo, L Bryant, Department of Medicine, University of Adelaide, Adelaide Australia

W Tam, Department of Gastroenterology, Royal Adelaide Hospital, Adelaide Australia

N Nguyen, Department of Gastroenterology, University of Adelaide, Adelaide, Australia

B Zacharakis, R Butler, G Davidson, Department of Gastroenterology, Women's and Children's Hospital, Adelaide Australia

M Horowitz, Department of Medicine, Royal Adelaide Hospital, Adelaide, Australia

Conflict of interest: None declared.

\section{REFERENCES}

1 Spapen HD, Duinslaeger L, Diltoer M, et al. Gastric emptying in critically ill patients is accelerated by adding cisapride to a standard enteral feeding protocol: results of a prospective randomised controlled trial. Crit Care Med 1995;23:481-5.

2 Heyland DK, Tougas G, King D, et al. Impaired gastric emptying in mechanically ventilated, critically ill patients. Intensive Care Med 1996;22:1339-44.

3 Kao CH, Chang Lai SP, Chieng PU, et al. Gastric emptying in head-injured patients. Am J Gastroenterol 1998;93:1108-12.

4 Ritz MA, Fraser R, Edwards $N$, et al. Delayed gastric emptying in ventilated critically ill patients: measurement by $13 \mathrm{C}$-octanoic acid breath test. Crit Care Med 2001;29:1744-9

5 Chapman M, Fraser R, Bartholomeusz F, et al. Gastric emptying in the critically ill: relationship between scintigraphic and carbon breath test measurement. Gastroenterology 2004;126:A488.

6 Heyland DK. Nutritional support of the critically ill patient. A critical review of the evidence. Crit Care Clin 1998;14:423-39.
7 Heyland DK, Cook DJ, Winder B, et al. Enteral nutrition in the critically ill patient: a prospective survey. Crit Care Med 1995;23:1055-60.

8 de Beaux I, Chapman M, Fraser R, et al. Enteral nutrition in the critically ill: A prospective survey in an Australian intensive care unit. Anaesth Intensive Care 2001:29:619-22

9 Engel JM, Muhling J, Junger A, et al. Enteral nutrition practice in a surgical intensive care unit: what proportion of energy expenditure is delivered enterally? Clin Nutr 2003;22:187-92.

10 Metheny N. Minimising respiratory complications of nasoenteric tube feeding: state of the science. Heart Lung 1993:22:213-23.

11 Inglis TJ, Sproat $\sqcup$, Sherratt MJ, et al. Gastroduodenal dysfunction as a cause of gastric bacterial overgrowth in patients undergoing mechanical ventilation of the lungs. Br J Anaesth 1992;68:499-502.

12 Brener W, Hendrix TR, McHugh PR. Regulation of the gastric emptying of glucose. Gastroenterology 1983;85:76-82.

13 Heddle R, Fone $D$, Dent J, et al. Stimulation of pyloric motility by intraduodenal dextrose in normal subjects. Gut 1988;29:1349-57.

14 Heddle R, Dent J, Read NW, et al. Antropyloroduodenal motor responses to intraduodenal lipid infusion in healthy volunteers. Am J Physiol Gastrointest Liver Physiol 1988;254:G671-9.

15 Edelbroek MA, Sun WM, Horowitz M, et al. Stereospecific effects of duodenal tryptophan on pyloric and duodenal motility in humans. Scand J Gastroenterol 1994:29:1088-95.

16 Heddle R, Collins PJ, Dent J, et al. Motor mechanisms associated with slowing of the gastric emptying of a solid meal by an intraduodenal lipid infusion. J Gastroenterol Hepatol 1989;4:437-47.

17 Tougas G, Anvari M, Dent J, et al. Relation of pyloric motility to pyloric opening and closure in healthy subjects. Gut 1992;33:466-71.

18 Lin HC. Abnormal intestinal feedback in disorders of gastric emptying. Dig Dis Sci 1994;39:54S-5

19 Horowitz M, Dent J. Disordered gastric emptying: mechanical basis, assessment and treatment. Baillieres Clin Gastroenterol 1991;5:371-407.

20 Mutlu GM, Mutlu EA, Factor P. GI complications in patients receiving mechanical ventilation. Chest 2001;119:1222-41.

21 Dive A, Moulart M, Jonard P, et al. Gastroduodenal motility in mechanically ventilated critically ill patients: a manometric study. Crit Care Med 1994;22:441-7.

22 Dive A, Miesse J, Jamart J, et al. Duodenal motor response to continuous enteral feeding is impaired in mechanically ventilated critically ill patients. Clin Nutr 1994; 13:302-6

23 Bosscha K, Nieuwenhuiis VB, Vos A, et al. Gastrointestinal motility and gastric tube feeding in mechanically ventilated patients. Crit Care Med 1998;26:1510-17.

24 Dive A, Foret $F$, Jamart J, et al. Effect of dopamine on gastrointestinal motility during critical illness. Intensive Care Med 2000;26:901-7.

25 Tournadre J-P, Barclay M, Fraser R, et al. Small intestinal motor patterns in critically ill patients after major abdominal surgery. Am J Gastroenterol $2001 ; 96: 2418-26$

26 Moore FA, Cocanour CS, McKinley BA, et al. Migrating motor complexes persist after severe traumatic shock in patients who tolerate enteral nutrition. J Trauma Injury Infect Critical Care 2001;51:1075-82.

27 Houghton LA, Read NW, Heddle R, et al. Motor activity of the gastric antrum, pylorus and duodenum under fasted conditions and after a liquid meal. Gastroenterology 1988;94:1276-84

28 Dent J. A new technique for continuous sphincter pressure measurement. Gastroenterology 1976:71:263-7.

29 Mathis C, Malbert CH. Gastric but not duodenal motor effects of oral erythromycin are dose related. Neurogastroenterol Motil 1995;7:47-54.

30 Mathis $\mathrm{C}$, Malbert $\mathrm{CH}$. Changes in pyloric resistance induced by erythromycin. Neurogastroenterol Motil 1998;10:131-8.

31 Andrews JM, Doran SM, Hebbard GS, et al. Nutrient-induced spatial patterning of human duodenal motor function. Am J Physiol Gastrointest Liver Physiol 2001;280:G501-9.

32 Defilippi CC, Gomez E. Continuous recording of pyloric sphincter pressure in dogs. Relationship to migratory motor complex. Dig Dis Sci 1985:30:669-74.

33 Chapman M, Fraser R, de Beaux I, et al. Cefazolin does not accelerate gastric emptying in the critically ill. Intensive Care Med 2003;29:1 169-72.

34 Ghoos YF, Maes BD, Geypens BJ, et al. Measurement of gastric emptying rate of solids by means of carbon-labelled octanoic breath test. Gastroenterology 1993;104:1640-7.

35 Anvari M, Dent J, Malbert C, et al. Mechanics of pulsatile transpyloric flow in the pig. J Physiol 1995;488:193-202.

36 Paterson CA, Anvari M, Tougas G, et al. Determinants of occurrence and volume of transpyloric flow during gastric emptying of liquids in dogs: importance of vagal input. Dig Dis Sci 2000;45:1509-16.

37 Ritz MA, Fraser R, Tam W, et al. Impacts and patterns of disturbed gastrointestinal function in critically ill patients. Am J Gastroenterol 2000;95:3044-52.

38 Stanghellini V, Malagelada JR, Zinsmeister AR, et al. Effect of opiate and adrenergic blockers on the gut motor response to centrally acting stimuli. Gastroenterology 1984;87:1 104-13

39 Thorn SE, Wattwil M, Lindberg G, et al. Systemic and central effects of morphine on gastroduodenal motility. Acta Anaesthesiol Scand 1996:40:177-86

40 Schirizek BA, Willacy LH, Kraglund K, et al. Antroduodenal motility, pH and gastric emptying during balanced anaesthesia: comparison of pethidine and fentanyl. Br J Anaesth 1989;62:674-82.

41 Chassard D, Lansiaux S, Duflo F, et al. Effects of subhypnotic doses of propofol on gastric emptying in volunteers. Anesthesiology 2002;97:96-101.

42 Hammas B, Hvarfner A, Thorn SE, et al. Propofol sedation and gastric emptying in volunteers. Acta Anaesthesiol Scand 1998;42:102-5. 
43 Rhoney DH, Parker D Jr, Formea CM, et al. Tolerability of bolus versus continuous gastric feeding in brain-injured patients. Neurol Res 2002;24:613-20.

44 Levein NG, Thorn SE, Wattwil M. Dopamine delays gastric emptying and prolongs orocaecal transit time in volunteers. Eur J Anaesthesiol 1999; 16:246-50.

45 Gati T, Gelencser F, Hideg J. The role of adrenergic receptors in the regulation of gastric motility in the rat. Z Exp Chir 1975;8:179-84.

46 Clark RA, Holdsworth CD, Rees Mr, et al. The effect on paracetamol absorption of stimulation and blockade of beta-adrenoceptors. $\mathrm{Br} J \mathrm{Clin}$ Pharmacol 1980;10:555-9.

47 Macintosh CG, Andrews JM, Jones KL, et al. Effects of age on concentrations of plasma cholecystokinin, glucagon-like peptide 1, and peptide YY and their relation to appetite and pyloric motility. Am J Clin Nutr 1999:69:999-1006.

48 Cook CG, Andrews JM, Jones KL, et al. Effects of small intestinal nutrient infusion on pyloric motility are modified by age. Am J Physiol Gastrointest Liver Physiol 1997;273:R755-61.

49 Fraser $\mathbf{R}$, Horowitz $M$, Dent J. Hyperglycaemia stimulates pyloric motility in normal subjects. Gut 1991;32:475-8.

50 Fraser RJ, Horowitz M, Maddox AF, et al. Hyperglycaemia slows gastric emptying in type 1 (insulin-dependent) diabetes mellitus. Diabetologia 1990;33:675-80

51 van den Berghe $G$, Wouters $P$, Weekers $F$, et al. Intensive insulin therapy in the critically ill patients. N Engl J Med 2001;345:1359-67.
52 Cunningham KM, Daly J, Horowitz $M$, et al. Gastrointestinal adaptation to diets of differing fat composition in human volunteers. Gut 1991;32:483-6. 53 Cunningham KM, Horowitz M, Read NW. The effect of short-term dietary supplementation with glucose on gastric emptying in humans. Br J Nutr 1991;65:15-19.

54 Horowitz M, Cunningham KM, Wishart J, et al. The effect of short-term dietary supplementation with glucose on gastric emptying of glucose and fructose and oral glucose tolerance in normal subjects. Diabetologia 1996:39:481-6.

55 Rigaud D, Bedig G, Merrouche M, et al. Delayed gastric emptying in anorexia nervosa is improved by completion of renutrition program. Dig Dis $\mathrm{Sci}$ 1988;33:919-25

56 Corvilain B, Abramowicz M, Fery F, et al. Effect of short term starvation on gastric emptying in normal and obese subjects-relationship to oral glucose tolerance. Am J Physiol Gastrointest Liver Physiol 1995;269:G512-17.

57 Beckoff K, Maclntosh CG, Chapman IM, et al. Effects of glucose supplementation on gastric emptying, blood glucose homeostasis, and appetite in the elderly. Am J Physiol Regul Integra Comp Physiol 2001;280:R570-6.

58 Dubois A, Gross HA, Ebert MH, et al. Altered gastric emptying and secretion in primary anorexia nervosa. Gastroenterology 1979;77:319-23.

59 Holt S, Ford MJ, Grant S, et al. Abnormal gastric emptying in primary anorexia nervosa. Br J Psychiatry 1981;139:550-2.

60 Robinson PH, Clarke M, Barrett J. Determinants of delayed gastric emptying in anorexia nervosa and bulimia nervosa. Gut 1988;29:458-64.

\section{EDITOR'S QUIZ: GI SNAPSHOT}

\section{Answer}

From question on page 1383

The diagnosis was mediastinal tumour presenting with Budd-Chiari syndrome.

Patients may present with acquired Budd-Chiari syndrome due to sudden or gradual occlusion of the hepatic veins, the inferior vena cava (IVC), or both. On examination, the patient may be jaundiced and display lower limb oedema. Shortness of breath may also be present secondary to decreased cardiac return. Liver function test results are non-specific and may show moderately elevated bilirubin and alkaline phosphatase levels. Various factors are known to be associated with hepatic or IVC thrombosis such as trauma, medications, congenital abnormalities, and neoplasms.

Mediastinal or pulmonary tumours may rarely cause obstruction of the IVC leading to development of BuddChiari syndrome. In this case the mediastinal tumour was a thymic carcinoma with metastases to the pericardium that caused IVC and hepatic venous thrombosis leading to the initial presentation with Budd-Chiari syndrome (fig 2).

doi: $10.1136 /$ gut.2005.066134

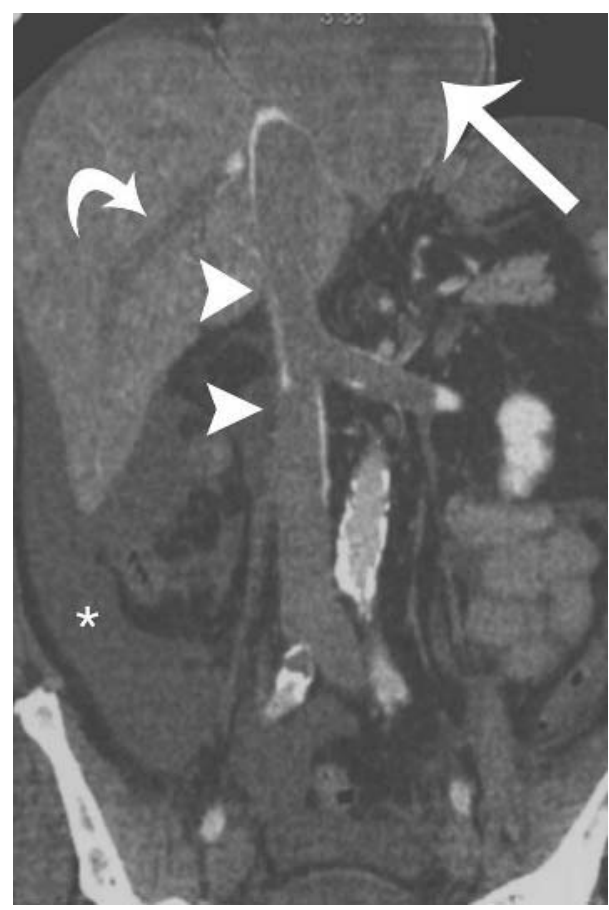

Figure 2 Coronal reformatted image along the plane of the inferior vena cava (IVC) shows the mediastinal mass (arrow) causing extensive thrombus in the IVC (arrowheads) and hepatic veins (curved arrow). Note ascitis $(*)$. 